\title{
Trading imbalances, predictable reversals, and cross-stock price pressure ${ }^{\text {th }}$
}

\author{
Sandro C. Andrade ${ }^{\mathrm{a}}$, Charles Chang ${ }^{\mathrm{b}}$, Mark S. Seasholes ${ }^{\mathrm{c}, *}$ \\ ${ }^{a}$ University of Miami, School of Business, P.O. Box 248094, Coral Gables, FL 33124, USA \\ ${ }^{\mathrm{b}}$ Cornell University, 435 Statler Hall, Ithaca, NY 14853, USA \\ ${ }^{\mathrm{c}}$ Santa Clara University, 500 El Camino Real - Finance, Santa Clara, CA 95053, USA
}

Received 6 March 2006; received in revised form 12 April 2007; accepted 24 April 2007

Available online 12 March 2008

\begin{abstract}
We test the implications of a multi-asset equilibrium model in which a finite number of risk-averse liquidity providers accommodate non-informational trading imbalances. These imbalances generate predictable reversals in stock returns. An imbalance in one stock also affects the prices of other stocks. The magnitude of the cross-stock price pressure depends on the correlations of the stocks' underlying cash flows. The model implies that non-informational trading increases the volatility of stock returns. We confirm the model's implications using data from the Taiwan Stock Exchange.
\end{abstract}

(C) 2008 Published by Elsevier B.V.

JEL classification: G12; G15

Keywords: Return reversals; Return predictability; Excess volatility

\section{Introduction}

This paper studies security pricing in the face of random, non-informational order flows. We present a multi-stock equilibrium model in which a finite number of risk-averse liquidity providers accommodate noninformational trading imbalances. As in single-stock models, liquidity providers are compensated via future price reversals. ${ }^{1}$

\footnotetext{
${ }_{2}^{2}$ We thank a national securities firm in Taiwan for providing the margin data, as well as Brad Barber, Neil Yi-Tsung Lee, Yu-Jane Liu, and Anlin Chen for contributing the time-series data of risk factors. Terry Hendershott and an anonymous referee have provided invaluable comments and suggestions. We are grateful to Malcolm Baker, Alex Boulatov, Brad DeLong, Greg Duffee, Darrell Duffie, Robin Greenwood, Ron Kaniel, Arvind Krishnamurthy, David Levine, Rich Lyons, Darius Miller, Stefan Nagel, Matt Pritsker, Avanidhar Subrahmanyam, Heather Tookes, and Masahiro Watanabe. We have benefited from participant comments at the Darden International Finance Conference, the NBER Conference on the Effect of Imperfect Trading on Security Prices, the 2006 WFA meetings, Goldman Sachs Asset Management, and Barclays Global Investors as well as the finance departments at Cornell University, Kellogg, Rice University, Stanford, U.C. Berkeley, University of Houston, U.T. Dallas, and University of Wisconsin.

*Corresponding author.

E-mail address: Mark.S.Seasholes@emailias.com (M.S. Seasholes).

${ }^{1}$ Examples of single-stock models include Amihud and Mendelson (1980), O'hara and Oldfield (1986), Grossman and Miller (1988), Campbell, Grossman, and Wang (1993), Spiegel and Subrahmanyam (1995), Holden and Subrahmanyam (2002), Llorente, Michaely,
} 
In our multi-stock framework, a demand shock for only one stock affects prices of other stocks due to the hedging desires of liquidity providers. The relative attractiveness of other stocks as hedging instruments depends on the correlation of their cash flows with the cash flows of the first stock. Therefore, the model implies that a demand shock in one stock has greater impact on the prices of more correlated stocks. To understand the transmission mechanism, consider a two-stock market. Suppose there is a non-informational order to buy stock $i$ and no orders to trade stock $j$. Risk-averse liquidity providers become sellers of stock $i$. They can partially offset the resulting position by buying stock $j$ whose cash flows are positively correlated with stock $i$ 's cash flows. Behaving competitively, liquidity providers bid up the price of stock $j$ and transmit part of stock $i$ 's initial price increase to stock $j$ - even in the absence of stock $j$ trading. Throughout the paper, price effects that are transmitted by liquidity providers across stocks are referred to as "cross-stock price pressure."

Our empirical analysis of price reactions to non-informational trading is motivated by the framework described in the paragraph above. We use weekly data from the Taiwan Stock Exchange ("TSE") to test implications and restrictions of the model. The data include all 607 listed stocks from January 1994 to August 2002. The exchange collects and publishes the number of shares of each stock held long in margin accounts at the end of every day. Margin accounts are owned by individual investors at local brokerage companies. Changes in margin account holdings are our proxy for the non-informational trading imbalances in the model. Regression analysis shows that positive trading imbalances in stock $i$ are linked to its price increasing and later reverting. The same trading imbalance is also linked to other stocks experiencing predictable price reversals. We show that this cross-stock price pressure is higher among stocks with more correlated cash flows than among stocks with less correlated cash flows. The model implies two sets of nonlinear restrictions on regression coefficients that are functions of cash flow correlations. We fail to reject the restrictions at all conventional levels, which shows that the relative magnitude of the observed cross-stock price pressure is consistent with model predictions.

We use a sorting procedure to quantify the economic magnitude of the price pressure and verify the robustness of regression results. Stocks are sorted based on weekly trading imbalances. The prices of stocks in the highest quintile (buys) increase, while the prices of stocks in the lowest quintile (sells) fall. The return difference between these two quintiles is 242 basis points (bp), on average. Prices then revert towards pre-sort levels over the next ten weeks. Both the magnitude and duration of the reversals are economically and statistically significant. Throughout the paper, we mitigate the possibility of spurious results arising from bidask bounce by using weekly returns that are measured starting with the opening price the week following a sort. Therefore, stocks are sorted into portfolios on the basis of trading imbalances from Monday to Friday, and returns are measured starting with the opening price the following Monday. Our approach addresses concerns that a large number of buy (sell) orders during a given week increases the probability that prices end the week at the ask (bid) price (see Blume and Stambaugh, 1983; Chordia and Subrahmanyam, 2004; Subrahmanyam, 2005b).

In addition, the model implies that stock returns experience "excess volatility." Stock returns are more volatile than underlying cash flows because random trading imbalances move stock prices away from their fundamental values. We show that, after controlling for cash flow volatilities, stocks with more volatile trading imbalances have more volatile returns.

Our analysis indicates that risk-averse traders are compensated for absorbing order imbalances. Liquidity is valuable and agents with a comparative advantage in providing liquidity can profit by doing so. Extending this line of reasoning, day traders and hedge funds potentially provide a socially valuable service (i.e., liquidity) as they seek profits and engage in short-term trading strategies. Second, our results suggest that excess stock price volatility is attributable at least in part to the fact that liquidity is valuable. Price movements beyond changes in underlying fundamentals could serve as a signal to liquidity providers as to where their services are needed.

(footnote continued)

Saar, and Wang (2002), Chordia and Subrahmanyam (2004), and Subrahmanyam (2005a, b). Our framework is a multi-stock extension of Grossman and Miller (1988) and Holden and Subrahmanyam (2002). 


\subsection{Related literature}

Our framework is a multi-stock extension of Grossman and Miller (1988). The framework also borrows from intertemporal, single-stock models such as Holden and Subrahmanyam (2002) and Chordia and Subrahmanyam (2004). ${ }^{2}$ As in these papers, we consider competitive liquidity providers. Liquidity providers/ market makers batch orders together and absorb excess demand, which results in a single clearing price (for each stock) at each point in time.

Another framework for modeling liquidity provision considers a market maker who receives a sequence of buy and sell orders. For each stock, the market maker posts a pair of bid and ask quotes indicating the prices at which he is willing to buy and sell shares. Multi-stock models in this framework have implications similar to the cross-stock price pressure implications of our framework. In Ho and Stoll (1983), for example, a sell trade in one stock raises the dealer's inventory in that stock. In order to reduce inventory levels, the dealer lowers that security's bid and ask prices relative to its true value, thus inducing other traders to buy. When the dealer trades more than one stock, he not only lowers the bid and ask quotes in the stock he recently bought but also adjusts quotes in other stocks to reduce his total inventory risk. The magnitude of quote adjustments in the other stocks depends on underlying correlations.

Empirical literature examining the price impact of liquidity demand can be divided into four strands. The first strand focuses on large rare events such as additions and deletions from stock indexes - see Harris and Gurel (1986), Shleifer (1986), Wurgler and Zhuravskaya (2002), and Greenwood (2005) for some examples. ${ }^{3}$ The second strand uses volume as a proxy for times when there are a large number of liquidity trades. Such papers include Campbell, Grossman, and Wang (1993), Llorente, Michaely, Saar, and Wang (2002), and Avramov, Chordia, and Goyal (2006). The third strand extends work with unsigned volume to signed order imbalances - see Chordia, Roll, and Subrahmanyam (2002, 2005), Chordia and Subrahmanyam (2004), Lee, Liu, Roll, and Subrahmanyam (2004), and Kaniel, Saar, and Titman (2008). ${ }^{4}$ Finally, an extensive literature includes direct examination of market maker inventories as well as tests of the single-stock models previously mentioned. Using 11 years of NYSE stocks, a recent paper by Hendershott and Seasholes (2007) confirms a pattern of predictable reversals that is similar to the reversals in our paper. A major difference between our paper and existing papers is that previous work has been motivated by single-stock models. We investigate cross-stock price pressure as well as implications for the excess volatility of returns.

Past work with Taiwanese data includes Lee, Liu, Roll, and Subrahmanyam (2004) who provide a thorough overview of the market. The authors study signed order imbalances aggregated across the 30 largest stocks in Taiwan. The authors find no evidence of autocorrelation in the daily order imbalances of large individual traders. Moreover, their evidence suggests that "large individuals are noise or liquidity traders." These findings are consistent with our results.

Finally, Harford and Kaul (2005) also study the relation between order imbalances and stock returns. While the authors include other stocks' imbalances in their regression analysis, our work differs from theirs in two fundamental ways. First, we use an explicit economic model to frame our empirical analysis. As a result, our regression coefficients can be interpreted in terms of structural parameters of the model. Second, we investigate the relation between trading imbalances and stock return volatility-something the earlier work does not address.

\footnotetext{
${ }^{2}$ Other models that study the dynamic interaction between liquidity providers and liquidity demanders include DeLong, Shleifer, Summers, and Waldman (1990a, b), Campbell, Grossman, and Wang (1993), Madhavan and Smidt (1993), Spiegel and Subrahmanyam (1995), Barberis and Shleifer (2003), and Greenwood (2007).

${ }^{3} \mathrm{~A}$ number of recent papers question the premise that index additions and deletions are unrelated to information. See Dhillon and Johnson (1991), Hegde and McDermott (2003), and Denis, McConnell, Ovtchinnikov, and Yu (2003) for discussions.

${ }^{4}$ Two additional papers focus on small trades as measured by trade size: Hvidkjaer (2006) and Barber, Odean, and Zhu (2006). The two papers do, however, provide complementary support for the idea that inventory risk helps explain reversals. Our data differ from those in Kaniel, Saar, and Titman (2008) who study all individual investor trades that are routed to the NYSE. The authors show that their sample of individual investors act as liquidity providers, trade against order flows, and are compensated via return reversals (particularly for buying). It is possible that individuals in the U.S. have stale limit orders (on average) which causes them to trade against price movements. The data used in our study, by contrast, are placed by active investors who demand liquidity.
} 
The paper proceeds as follows. Section 2 presents our model and Section 3 describes the data. Section 4 provides the main results of the paper regarding trading imbalances, predictable reversals, and cross-stock price pressure. Section 5 tests an additional cross-sectional implication of our model regarding the excess volatility of returns, and Section 6 concludes.

\section{Model}

There are three stocks labeled $\{i, j, k\}$, each in unit supply, and a riskless asset in elastic supply. The riskless interest rate is zero and the price of the riskless asset is one. Extending the model to more assets is straightforward.

There are three dates. Agents trade at date 1 and date 2. Each stock pays a single liquidating cash flow equal to $S_{1}^{i}+S_{2}^{i}+\Phi_{3}^{i}$ at date 3 . This cash flow is gradually revealed over time: $S_{1}^{i}$ is revealed at date $1, S_{2}^{i}$ at date 2, and $\Phi_{3}^{i}$ at date 3. All components of the liquidating cash flow are normally distributed: $S_{1}^{i} \sim \mathrm{N}\left(0, V_{s}\right) ; S_{2}^{i} \sim \mathrm{N}\left(0, V_{s}\right) ;$ and $\Phi_{3}^{i} \sim \mathrm{N}\left(0, V_{\phi}\right)$. Stock $i$ 's cash flow components are serially uncorrelated. Similar notation and assumptions hold for stocks $j$ and $k$. We envision more time between dates 2 and 3 than between dates 1 and 2, so that $V_{\phi}>V_{s}$. The use of two "nearby"periods and one "distant" period is for analytical simplicity. Similar qualitative results would be obtained if there were many time periods of the same length.

Cash flow components are contemporaneously correlated across stocks. For stocks $i$ and $j$, the crosssectional correlation of each cash flow component is denoted $\rho_{\phi}^{*}$. The correlations associated with stock pairs $\{i, k\}$ and $\{j, k\}$ are both $\rho_{\phi}^{* *}$ such that $\rho_{\phi}^{* *}<\rho_{\phi}^{*}$. Throughout the paper, it is assumed that stocks $i$ and $j$ are from the same industry and have more correlated cash flows than stocks $i$ and $k$ which are from different industries. Section 3 shows that firm cash flows from ongoing operations (e.g., operating profits) are significantly more correlated within industry than across industries.

There are two groups of agents. The first group is composed of non-informational traders who place inelastic orders for stocks $i, j$, and $k$ at dates 1 and 2. The first group's net order flow for stock $i$ at date $t$ is denoted $Z_{t}^{i} \sim \mathrm{N}\left(0, V_{z}^{i}\right)$. We refer to $Z_{t}^{i}$ as the non-informational trading imbalance of stock $i$ at date $t$ and it represents the change in demand of the non-informational traders. This imbalance is uncorrelated with any cash flow component of any stock. Imbalances are not serially correlated over time: $\operatorname{Corr}\left(Z_{1}^{i}, Z_{2}^{i}\right)=0$ with similar expressions for stocks $j$ and $k$. However, trading imbalances are contemporaneously correlated across stocks with $\rho_{Z} \equiv \operatorname{Corr}\left(Z_{t}^{i}, Z_{t}^{j}\right)=\operatorname{Corr}\left(Z_{t}^{i}, Z_{t}^{k}\right)=\operatorname{Corr}\left(Z_{t}^{j}, Z_{t}^{k}\right)$.

The second group of agents is composed of a finite number of competitive, risk-averse investors. This group is referred to as liquidity providers. The investors have CARA utility with risk-aversion coefficient $\lambda$ and they maximize the expected utility of date 3 wealth. For each stock $i$, they observe $S_{1}^{i}$ at date $1, S_{2}^{i}$ at date 2 , and $\Phi_{3}^{i}$ at date 3. One can think of $\lambda$ as being equal to $\bar{\lambda} / A$, where $\bar{\lambda}$ is the absolute risk aversion coefficient of each liquidity provider and $A$ is the total number of liquidity providers. The risk-bearing capacity of the market is unlimited if either $\bar{\lambda}$ goes to zero or $A$ goes to infinity.

\subsection{Equilibrium prices and returns}

Let $P_{t}^{i}$ be the price of stock $i$ at date $t$. We solve for equilibrium prices by backward induction (please see Appendix A for details).

$$
\begin{aligned}
P_{3}^{i}= & S_{1}^{i}+S_{2}^{i}+\Phi_{3}^{i} \\
P_{2}^{i}= & S_{1}^{i}+S_{2}^{i}+\lambda V_{\phi}\left(Z_{1}^{i}+Z_{2}^{i}\right)+\rho_{\phi}^{*} \lambda V_{\phi}\left(Z_{1}^{j}+Z_{2}^{j}\right)+\rho_{\phi}^{* *} \lambda V_{\phi}\left(Z_{1}^{k}+Z_{2}^{k}\right)-\lambda\left(1+\rho_{\phi}^{*}+\rho_{\phi}^{* *}\right) V_{\phi} \\
P_{1}^{i}= & S_{1}^{i}+\lambda\left(V_{\phi}+V_{s}\right) Z_{1}^{i}+\rho_{\phi}^{*} \lambda\left(V_{\phi}+V_{s}\right) Z_{1}^{j}+\rho_{\phi}^{* *} \lambda\left(V_{\phi}+V_{s}\right) Z_{1}^{k} \\
& -\lambda\left(1+\rho_{\phi}^{*}+\rho_{\phi}^{* *}\right)\left(V_{\phi}+V_{s}\right)
\end{aligned}
$$


We follow the literature and interpret stock price changes as stock returns. Stock $i$ 's return from date 1 to 2 is given by

$$
\begin{aligned}
P_{2}^{i}-P_{1}^{i}= & S_{2}^{i}+\lambda V_{\phi} Z_{2}^{i}+\rho_{\phi}^{*} \lambda V_{\phi} Z_{2}^{j}+\rho_{\phi}^{* *} \lambda V_{\phi} Z_{2}^{k} \\
& -\lambda V_{s} Z_{1}^{i}-\rho_{\phi}^{*} \lambda V_{s} Z_{1}^{j}-\rho_{\phi}^{* *} \lambda V_{s} Z_{1}^{k}+\lambda\left(1+\rho_{\phi}^{*}+\rho_{\phi}^{* *}\right) V_{s} .
\end{aligned}
$$

Eq. (2), relating stock $i$ 's return to cash flow news and trading imbalances, contains the main results of the model. The first four terms of the equation represent the surprise part of the return: (i) news about stock $i$ 's cash flow; (ii) stock $i$ 's trading imbalance; (iii) stock $j$ 's trading imbalance; and (iv) stock $k$ 's trading imbalance. The last four terms represent the risk premium earned by holders of stock $i$. Terms five, six, and seven represent a conditional risk premium that liquidity providers earn for absorbing last period's trading imbalances. The last term represents stock $i$ 's unconditional risk premium.

Eq. (2) is extrapolated from three to $N^{*}+N^{* *}+1$ stocks. We assume that $N^{*}$ stocks are from the same industry as stock $i$ and have the same cash flow correlation $\left(\rho_{\phi}^{*}\right)$ with stock $i$. Similarly, $N^{* *}$ stocks are from other industries and have the same cash flow correlation $\left(\rho_{\phi}^{* *}\right)$ with stock $i$ such that $\rho_{\phi}^{* *}<\rho_{\phi}^{*}$.

$$
\begin{aligned}
P_{2}^{i}-P_{1}^{i}= & S_{2}^{i}+\lambda V_{\phi} Z_{2}^{i}+\lambda V_{\phi} \rho_{\phi}^{*} \sum Z_{2}^{*}+\lambda V_{\phi} \rho_{\phi}^{* *} \sum Z_{2}^{* *} \\
& -\lambda V_{s} Z_{1}^{i}-\lambda V_{s} \rho_{\phi}^{*} \sum Z_{1}^{*}-\lambda V_{s} \rho_{\phi}^{* *} \sum Z_{1}^{* *}+\lambda\left(1+N^{*} \rho_{\phi}^{*}+N^{* *} \rho_{\phi}^{* *}\right) V_{s} .
\end{aligned}
$$

where $\sum Z_{t}^{*}$ is the sum of the $N^{*}$ trading imbalances on date $t$, and $\sum Z_{t}^{* *}$ is the sum of the $N^{* *}$ trading imbalances. Eq. (3) shows that stock $i$ 's returns are related to the contemporaneous and lagged trading imbalances of all stocks in the market. In reduced form, Eq. (3) becomes our main estimation equation:

$$
r_{t}^{i}=\pi_{0}+\pi_{11} Z_{t}^{i}+\pi_{12} \sum Z_{t}^{*}+\pi_{13} \sum Z_{t}^{* *}+\pi_{21} Z_{t-1}^{i}+\pi_{22} \sum Z_{t-1}^{*}+\pi_{23} \sum Z_{t-1}^{* *}+\varepsilon_{t}^{i}
$$

There is a direct mapping from regression coefficients $\left\{\pi_{11} \ldots \pi_{23}\right\}$ in Eq. (4) to the model's structural parameters $\left\{\lambda, V_{\phi}, V_{s}, \rho_{\phi}^{*}, \rho_{\phi}^{* *}\right\}$ in Eq. (3). This mapping implies two sets of nonlinear restrictions on the regression coefficients. In Section 4, we use data from the Taiwan Stock Exchange to estimate the regression coefficients and test the restrictions. The next section describes the data.

\section{Data}

We use data from the Taiwanese Stock Exchange (TSE) to test the implications of the model in Section 2. This section describes the data sources and defines variables. Section 3.1 discusses the suitability of using trading imbalances from the TSE as a proxy for the model's non-informational trading imbalances.

All data originate from the Taiwan Stock Exchange. The data start on January 1, 1994 and end August 29, 2002. We use a weekly frequency throughout the paper and the sample period consists of 451 calendar weeks. The sample contains the 607 listed companies for which some return and trading data exist during the sample period.

Holdings and trading data: We obtain the aggregate number of shares of each stock held long in margin accounts at the end of each week. The margin accounts are owned by individual investors at local brokerage firms. The TSE aggregates holdings data for each stock across all margin accounts and across all brokerage firms. The data are available on the exchange's website two hours after the market closes each trading day. Therefore, all investors are able to observe the number of shares held in margin accounts a few times during the week. In order to compare holding quantities across stocks, we normalize by shares outstanding:

$$
H_{t}^{i} \equiv \frac{\text { Shares Held Long in Margin Accounts } s_{t}^{i}}{\text { Total Shares Outstanding }}{ }_{t}^{i}
$$

We use the weekly change in shares held in margin accounts (normalized) as a proxy for the model's noninformational trading imbalances:

$$
Z_{t}^{i} \equiv \Delta H_{t}^{i}=\frac{\text { Net Shares Bought }(\text { Sold })_{t}^{i}}{\text { Total Shares Outstanding }}{ }_{t}^{i}
$$


Table 1

Descriptive statistics of trading imbalances

Panel A provides descriptive cross-sectional statistics of trading imbalances and aggregate holdings in our sample at the individual stock level. $Z_{t}^{i}$ is the measure of trading imbalances for stock $i$ over a week $t .\left|Z_{t}^{i}\right|$ is the absolute value of trading imbalances. $H_{t}^{i}$ is the measure of holdings for stock $i$ at the end of week $t$. Construction of the measures is described in the text. Panel B presents the estimates for the autocorrelation of the trading imbalances $Z_{t}^{i}$. The null hypothesis of zero autocorrelation for stock $i$ is tested with White standard errors. The full sample contains 607 firms and 451 weeks of data. The sample period starts 05-Jan-1994 and ends 29-Aug-2002. Data are from the Taiwan Economic Journal.

Panel A: Weekly cross-sectional measures

\begin{tabular}{lrrr}
\hline & $\begin{array}{r}Z_{t}^{i} \\
(\mathrm{bp})\end{array}$ & $\begin{array}{r}\left|Z_{t}^{i}\right| \\
(\mathrm{bp})\end{array}$ & $\begin{array}{r}H_{t}^{i} \\
(\%)\end{array}$ \\
\hline Average & 3.45 & 41.98 & 8.42 \\
Std. Dev. & 19.25 & 16.60 & 2.19 \\
25th ptile & -21.59 & 8.33 & 3.79 \\
50th ptile & -1.83 & 22.09 & 7.58 \\
75th ptile & 21.48 & 50.82 & 12.30 \\
$N$ (Firms) & 607 & 607 & 607 \\
$T$ (Weeks) & 451 & 451 & 451
\end{tabular}

Panel B: Weekly autocorrelation measures

\begin{tabular}{lc}
\hline Average $\theta_{1}^{i}$ from the regression & $Z_{t}^{i}=a^{i}+\theta_{1}^{i} Z_{t-1}^{i}+\varepsilon_{t}^{i}$ \\
Std. Err. of Average & 0.129 \\
25th-tile & 0.01 \\
50th-tile & 0.111 \\
75th-tile & 0.187 \\
$\%$ of Firms Where We Fail to Reject $H_{0}: \theta_{1}^{i}=0$ at the 5\% Level & $76 \%$ \\
$N$ & 607 \\
$T$ & Varies by Firm \\
\hline
\end{tabular}

Table 1, Panel A shows weekly cross-sectional measures of $Z_{t}^{i}$, $\left|Z_{t}^{i}\right|$, and $H_{t}^{i}$. Companies have an average trading imbalance $\left(Z_{t}^{i}\right)$ of $3.45 \mathrm{bp}$ per week and a median $Z_{t}^{i}$ of $-1.83 \mathrm{bp}$ per week. The inter-quartile range of $Z_{t}^{i}$ is $-21.59 \mathrm{bp}$ to $+21.48 \mathrm{bp}$. Trading imbalances are volatile and the average $\left|Z_{t}^{i}\right|$ is 41.98 basis point per week. The inter-quartile range of $\left|Z_{t}^{i}\right|$ is $8.33 \mathrm{bp}$ to $50.82 \mathrm{bp}$. On average, $8.42 \%$ of a firm's shares outstanding are held in margin accounts.

We test whether the weekly trading imbalances in a given stock $\left(Z_{t}^{i}\right)$ are autocorrelated. Table 1, Panel B shows that the null hypothesis of zero autocorrelation of weekly trading imbalances cannot be rejected for $76 \%$ of the firms. The average $A R(1)$ coefficient is 0.129 , but estimates are noisy at the firm level.

Price and return data: We obtain share prices, returns, and number of shares outstanding for each listed stock. Returns reflect dividend distributions and are adjusted for capital changes. We use weekly open-to-open stock returns so that results are not spuriously driven by bid-ask bounce.

Financial data and industry classification: We group firms by the correlation of underlying cash flows in order to study cross-stock price pressure. Firms are typically grouped using TSE industry designations because cash flows are more correlated for a pair of firms from the same industry than for a pair from different industries. Alternatively, firms are grouped by the correlation of cash flows estimated from financial data (e.g., correlation of gross profits). We obtain quarterly sales, gross profits, operating profits, and net income for TSE firms. The financial data start 1995Q1 and end 2004Q4. The data are available for 503 (none of which is a financial company) of the 607 firms in our sample. The results of this paper are not sensitive to the grouping procedure.

Table 2 shows the average pairwise correlation of cash flows estimated from financial data. Correlations are significantly higher for firms in the same industry than for firms in different industries. For example, the 
Table 2

Pairwise correlation of ongoing operations

This table shows the average pairwise correlation of ongoing operations for firms in our sample. The table also reports the average pairwise correlation for two firms within the same industry and two firms from different industries. We use 39 quarters of reporting data for the measures of ongoing operations. All measures are in Taiwanese dollars (NTD). The sample period starts $1995 \mathrm{Q} 1$ and ends $2004 \mathrm{Q} 4$. Data are from the Taiwan Economic Journal.

\begin{tabular}{|c|c|c|c|c|c|}
\hline Measure & $\begin{array}{l}\text { Average correlation } \\
\text { all firms }\end{array}$ & $\begin{array}{l}\text { Avg. corr. } \\
\text { within industry }\end{array}$ & $\begin{array}{l}\text { Avg. corr. } \\
\text { across industry }\end{array}$ & $\begin{array}{c}\text { Difference within } \\
\text { vs. across }\end{array}$ & $\begin{array}{l}\text { Ratio within } \\
\quad \div \text { across }\end{array}$ \\
\hline Sales & 0.1692 & 0.3153 & 0.1420 & $0.1733^{* * *}$ & 2.22 \\
\hline Gross profits & 0.0602 & 0.1532 & 0.0429 & $0.1103^{* * *}$ & 3.57 \\
\hline Operating profits & 0.0374 & 0.0831 & 0.0290 & $0.0541^{* * *}$ & 2.87 \\
\hline Net profits & 0.0525 & 0.0985 & 0.0440 & $0.0545^{* * *}$ & 2.24 \\
\hline Gross profit margin & 0.0596 & 0.1191 & 0.0485 & $0.0706^{* * *}$ & 2.46 \\
\hline Operating profit margin & 0.0167 & 0.0500 & 0.0105 & $0.0395^{* * *}$ & 4.76 \\
\hline Net profit margin & 0.0111 & 0.0229 & 0.0088 & $0.0141^{* * *}$ & 2.60 \\
\hline
\end{tabular}

*** Indicates significance at the $1 \%$ level.

average correlation of gross profits is 0.1532 for firms in the same industry and 0.0429 for firms in different industries. The within-industry versus across-industry difference is statistically different from zero at the $1 \%$ level for all measures. The ratio of within-industry correlation to across-industry correlation ranges from 2.22 (sales) to 4.76 (operating profit margin).

\subsection{The proxy for trading imbalances}

We use the weekly change in shares held in margin accounts as a proxy for the model's non-informational trading imbalances $\left(Z_{t}^{i}\right)$. There are four pieces of evidence supporting this identification strategy. First, the model assumes that trading imbalances are serially uncorrelated with a mean of zero. Table 1, Panel A shows that the mean and median of the margin trading imbalances are close to zero and the distribution is roughly symmetric. Panel B shows that we fail to reject the null hypothesis of no serial correlation for $76 \%$ of the stocks.

Second, the model assumes that non-informational trading imbalances are uncorrelated with future cash flows. Transaction-level data from the TSE (not available to the authors) confirm that $99.3 \%$ of trades through margin accounts are done by individuals. ${ }^{5}$ Several papers advance the idea that individuals trade for reasons unrelated to stock fundamentals - see Barber and Odean (2000). In the case of Taiwan, the evidence seems particularly compelling. Barber, Lee, Liu, and Odean (2005) estimate that individual investors in Taiwan turn their entire portfolio over three to six times per year. They also show that individual investors' returns are reduced by $3.5 \%$ per year before fees as a result of the high turnover. We examine the aggregate portfolio performance of all shares held in margin accounts $\left(H_{t}^{i}\right)$ and rebalance each week. The portfolio underperforms the Taiwanese market portfolio by $10.97 \mathrm{bp}$ per week (more than $5 \%$ per year) during our eight-year sample period and before accounting for fees. The beta of the portfolio is 1.07 and the alpha is $-9.74 \mathrm{bp}$ per week ( $t$-statistic is 1.91 ). The turnover of the portfolio is about $250 \%$ per year. Untabulated results (available upon request) show that margin trading imbalances are uncorrelated with economic variables such as the six-month money market rate and the level of lending in the domestic banking system.

Third, the model assumes that the non-informational trading imbalances are liquidity-demanding orders. Barber, Lee, Liu, and Odean (2005) use transaction-level data from the TSE to classify each trade as "passive" (liquidity-providing) or "aggressive" (liquidity-demanding). According to their methodology, approximately $90 \%$ of the trades through margin accounts in Taiwan can be classified as either passive or aggressive. Of these, $80 \%$ are classified as aggressive or liquidity-demanding.

\footnotetext{
${ }^{5} \mathrm{We}$ do not have access to TSE transaction-level data. These results, as well as the trade classification result reported in the following paragraph, are generously provided by the authors of Barber, Lee, Liu, and Odean (2005).
} 
Fourth, our empirical methodology could have low power to detect buying or selling pressure if the trading imbalances constitute a small fraction of the total trading volume on the TSE. This is not the case, however, for the 134 stocks with nonzero margin holdings for all 451 weeks, trades through margin accounts comprise $42.36 \%$ of total trading volume.

\section{Results}

We use data from the Taiwan Stock Exchange to test implications of the model in Section 2. Section 4.1 estimates the regression coefficients in Eq. (4). Section 4.2 tests implications of the model regarding the signs and magnitudes of regression coefficients. In Section 4.3, stocks are sorted into portfolios based on trading imbalances and the returns of buy-and-hold portfolios are computed. The sorting procedure helps to quantify the economic magnitudes of return reversals and cross-stock price pressure.

\subsection{Regression results}

The model implies that stock returns are positively related to contemporaneous own-trading imbalances, and negatively related to lagged own-trading imbalances. These implications can be derived from Eq. (2):

$$
\begin{aligned}
& \operatorname{Cov}\left[P_{2}^{i}-P_{1}^{i}, Z_{2}^{i}\right]=\lambda V_{\phi}\left(V_{z}^{i}\right)^{\frac{1}{2}}\left[\left(V_{z}^{i}\right)^{\frac{1}{2}}+\rho_{\phi}^{*} \rho_{z}\left(V_{z}^{j}\right)^{\frac{1}{2}}+\rho_{\phi}^{* *} \rho_{z}\left(V_{z}^{k}\right)^{\frac{1}{2}}\right]>0 \\
& \operatorname{Cov}\left[P_{2}^{i}-P_{1}^{i}, Z_{1}^{i}\right]=-\lambda V_{s}\left(V_{z}^{i}\right)^{\frac{1}{2}}\left[\left(V_{z}^{i}\right)^{\frac{1}{2}}+\rho_{\phi}^{*} \rho_{z}\left(V_{z}^{j}\right)^{\frac{1}{2}}+\rho_{\phi}^{* *} \rho_{z}\left(V_{z}^{k}\right)^{\frac{1}{2}}\right]<0
\end{aligned}
$$

Table 3, Regression 1 confirms both implications $\left(\hat{\pi}_{11}=2.0383\right.$ and $\left.\hat{\pi}_{21}=-0.3630\right)$. Both regression coefficients are statistically different from zero at the $1 \%$ level. Due to the panel nature of our data, we use standard errors robust to heteroskedasticity and contemporaneous cross-sectional correlation of residuals. ${ }^{6}$ As in Chordia and Subrahmanyam (2004), contemporaneous and lagged own-stock trading imbalances affect a stock's return. Note that the adjusted $R^{2}$ of Regression 1 is 0.0370 .

Table 3, Regression 2 reports the coefficient estimates from Eq. (4). Individual stock returns are regressed on own-stock trading imbalances and other stocks' trading imbalances. Stock $i$ 's returns are positively related to stock $i$ 's contemporaneous trading imbalances $\left(\hat{\pi}_{11}=0.9989\right)$, positively related to same-industry stocks' contemporaneous imbalances $\left(\hat{\pi}_{12}=0.1126\right)$, and positively related to different-industry stocks' contemporaneous imbalances $\left(\hat{\pi}_{13}=0.0392\right)$. Stock $i$ 's returns are negatively related to stock i's lagged trading imbalances $\left(\hat{\pi}_{21}=-0.3297\right)$, negatively related to same-industry stocks' lagged imbalances $\left(\hat{\pi}_{22}=-0.0368\right)$, and negatively related to different-industry stocks' lagged imbalances $\left(\hat{\pi}_{23}=-0.0185\right)$. Each of the six regression coefficients is significant at the $1 \%$ level. Our model prescribes including both own-stock and other stocks' trading imbalances in return regressions. The significant coefficient estimates shown in Regression 2 along with the increase in adjusted $R^{2}$ from 0.0370 to 0.2094 support this prescription.

Table 3, Panel B provides the results of two alternative regression specifications. Alternative A introduces a new method of differentiating between firm pairs with high cashflow correlations $\left(\sum Z_{t}^{*}\right)$ and firm pairs with low cashflow correlations $\left(\sum Z_{t}^{* *}\right)$. Rather than using the TSE industries to group firms, Alternative A uses correlations estimated from financial data. For each firm $i$, we calculate the pairwise correlations of $i$ 's gross profits with every other firm's gross profits. We define $\sum Z_{t}^{*}$ to be the sum of the trading imbalances of the 25 firms whose gross profits are most correlated with firm $i$ 's gross profits. The trading imbalances of the remaining stocks are included in $\sum Z_{t}^{* *}$. The regression results shown in Alternative $\mathrm{A}$ are not economically different from those in Regression 2, indicating that the results are not sensitive to the grouping criterion.

Table 3, Alternative B adds explanatory variables to Regression 2 to check the robustness of the results. We include lagged returns of stock $i\left(r_{t-1}^{i}\right.$ and $\left.r_{t-2}^{i}\right)$, lagged returns of a portfolio of same-industry stocks $\left(r_{t-1}^{*}\right.$ and $\left.r_{t-2}^{*}\right)$, lagged returns of different-industry stocks $\left(r_{t-1}^{* *}\right.$ and $\left.r_{t-2}^{* *}\right)$, and additional lagged trading imbalances

\footnotetext{
${ }^{6}$ See Petersen (2007) for an overview. Footnote 8 of Petersen's paper provides a formula for the clustered standard errors. Tables report $t$-statistics based on two-sided tests (conservative for hypotheses regarding coefficient signs).
} 
Table 3

Price impacts, reversals, and cross-stock price pressure

This table presents the results of a pooled OLS regression of stock $i$ 's weekly return $\left(r_{t}^{i}\right)$ on: its own contemporaneous trading imbalance (coef. $\pi_{11}$ on $Z_{t}^{i}$ ); stock $i$ 's industry trading imbalance excluding stock $i$ 's imbalance (coef. $\pi_{12}$ on $Z_{t}^{*}$ ); the rest of the market's trading imbalance excluding stock $i$ 's industry (coef. $\pi_{13}$ on $Z_{t}^{* *}$ ); stock $i$ 's own lagged trading imbalance (coef. $\pi_{21}$ on $Z_{t-1}^{i}$ ); stock $i$ 's industry lagged (coef. $\pi_{22}$ on $Z_{t-1}^{*}$ ); and the rest of the market's lagged trading imbalance (coef. $\pi_{23}$ on $Z_{t-1}^{* *}$ ). Panel A presents the main regression results, while Panel B presents two alternative regressions (robustness checks). There are 607 stocks and 20 industries in the full sample. The sample period starts 05-Jan-1994 and ends 29-Aug-2002. Data are from the Taiwan Economic Journal. T-statistics are based on Roger's standard errors that allow for heteroskedasticity and clustering of contemporaneous observations.

\begin{tabular}{|c|c|c|c|c|c|}
\hline & & \multicolumn{2}{|c|}{ Panel A } & \multicolumn{2}{|c|}{ Panel B } \\
\hline & & Reg. 1 & Reg. 2 & Alt. A & Alt. B \\
\hline \multirow[t]{2}{*}{$\pi_{11}$} & Own Imbalance $\left(Z_{t}^{i}\right)$ & 2.0383 & 0.9989 & 1.0924 & 1.0121 \\
\hline & $(T$-stat) & (16.57) & $(17.35)$ & (18.08) & (17.38) \\
\hline \multirow[t]{2}{*}{$\pi_{12}$} & Same Industry $\left(Z_{t}^{*}\right)$ & & 0.1126 & 0.1366 & 0.1147 \\
\hline & $(T$-stat $)$ & & $(13.49)$ & $(9.12)$ & $(12.46)$ \\
\hline \multirow[t]{2}{*}{$\pi_{13}$} & Diff. Industry $\left(Z_{t}^{* *}\right)$ & & 0.0392 & 0.0537 & 0.0402 \\
\hline & $(T$-stat $)$ & & $(12.20)$ & $(14.42)$ & $(12.15)$ \\
\hline \multirow[t]{2}{*}{$\pi_{21}$} & Lagged Own Imbalance $\left(Z_{t-1}^{i}\right)$ & -0.3630 & -0.3297 & -0.3171 & -0.3047 \\
\hline & $(T-$ stat $)$ & $(-3.85)$ & $(-7.76)$ & $(-6.77)$ & $(-7.22)$ \\
\hline \multirow{2}{*}{$\pi_{22}$} & Lagged Same Industry $\left(Z_{t-1}^{*}\right)$ & & -0.0368 & -0.0397 & -0.0294 \\
\hline & $(T$-stat) & & $(-4.21)$ & $(-2.94)$ & $(-2.83)$ \\
\hline \multirow[t]{4}{*}{$\pi_{23}$} & Lagged Diff. Industry $\left(Z_{t-1}^{* *}\right)$ & & -0.0185 & -0.0237 & -0.0137 \\
\hline & $(T$-stat $)$ & & $(-5.56)$ & $(-5.73)$ & $(-3.19)$ \\
\hline & Notes & & & $\begin{array}{l}\text { Groupings based } \\
\text { on empir corr }\end{array}$ & $\begin{array}{c}\text { Incl: } r_{t-1}, r_{t-2}, Z_{t-2} \\
\text { as } R H S \text { vars }\end{array}$ \\
\hline & $\operatorname{Adj} . R^{2}$ & 0.0370 & 0.2094 & 0.1930 & 0.2161 \\
\hline
\end{tabular}

$\left(Z_{t-2}^{i}, Z_{t-2}^{*}\right.$, and $\left.Z_{t-2}^{* *}\right)$. The estimated coefficients $\left(\hat{\pi}_{11} \ldots \hat{\pi}_{23}\right)$ are not economically different from those in Regression 2 in Panel A. ${ }^{7}$

\subsection{Statistical tests of model implications}

We test three sets of model implications. First, if the average correlation of firms' cash flows is positive (as shown in Table 2) and liquidity providers are risk averse, the model predicts that the contemporaneous coefficients $\left\{\hat{\pi}_{11}, \hat{\pi}_{12}, \hat{\pi}_{13}\right\}$ should be positive, while the lagged coefficients $\left\{\hat{\pi}_{21}, \hat{\pi}_{22}, \hat{\pi}_{23}\right\}$ should be negative. Estimated coefficients in Table 3, Regression 2 confirm these predictions. Economically, the pattern of positive and negative coefficients imply that own-stock and other stocks' trading imbalances generate predictable price reversals.

Second, the model predicts that the magnitude of cross-stock price pressure is higher when stocks' underlying cash flows are more correlated. Table 3, Regression 2 shows that the coefficient on same-industry imbalances $\left(\hat{\pi}_{12}=0.1126\right)$ is 2.87 times larger than the coefficient on different-industry imbalances $\left(\hat{\pi}_{13}=0.0392\right)$. The null hypothesis that $\hat{\pi}_{12}=\hat{\pi}_{13}$ is rejected at the $1 \%$ level. We obtain similar results using the coefficients on lagged trading imbalances. The same-industry lagged coefficient $\left(\hat{\pi}_{22}=-0.0368\right)$ is 1.99 times larger than the different-industry lagged coefficient $\left(\hat{\pi}_{23}=-0.0185\right)$. The null hypothesis that $\hat{\pi}_{12}=\hat{\pi}_{13}$ is rejected at the $5 \%$ level.

\footnotetext{
${ }^{7}$ Six sets of robustness checks are available upon request: (i) returns in excess of the risk-free rate used as the dependent variable in Regression 2; (ii) trading imbalances measured in millions of Taiwanese dollars as opposed to the normalized measure $Z_{t}^{i}$; (iii) an alternative normalization of trading imbalances $Z_{t}^{i} \equiv H_{t}^{i} / H_{t-1}^{i}-1$; (iv) regression 2 estimated using only the balanced panel of 134 described in 2; (v) Regression 2 estimated using only data from the 50 largest stocks; and (vi) Regression 2 estimated for four nonoverlapping subperiods. All six sets of results are economically similar to those shown in Table 3, Regression 2.
} 
Third, Eqs. (3) and (4) imply two sets of nonlinear restrictions on regression coefficients:

$$
\begin{aligned}
& \frac{\pi_{12}}{\pi_{11}}=\frac{\rho_{\phi}^{*} \lambda V_{\phi}}{\lambda V_{\phi}}=\rho_{\phi}^{*}=\frac{\rho_{\phi}^{*} \lambda V_{s}}{\lambda V_{s}}=\frac{\pi_{22}}{\pi_{21}} . \\
& \frac{\pi_{13}}{\pi_{11}}=\frac{\rho_{\phi}^{* *} \lambda V_{\phi}}{\lambda V_{\phi}}=\rho_{\phi}^{* *}=\frac{\rho_{\phi}^{* *} \lambda V_{s}}{\lambda V_{s}}=\frac{\pi_{23}}{\pi_{21}} .
\end{aligned}
$$

We test these restrictions using nonlinear Wald tests and the coefficients of Table 3, Regression 2. We fail to reject the restriction in Eq. (5) at conventional levels ( $p$-value $=0.9744)$, fail to reject the restriction in Eq. (6) $(p=0.1681)$, and fail to reject the joint set of restrictions $(p=0.2199)$. Estimated regression coefficients show that the relative magnitudes of predictable reversals associated with own-stock and other stocks' trading imbalances are consistent with the model in Section 2.

\subsection{Sort results}

We sort stocks into quintiles based on weekly trading imbalances $\left(Z_{t}^{i}\right)$ in order to quantify the economic magnitude of predictable reversals. We then form equal-weighted portfolios of stocks in each $Z_{t}^{i}$ quintile and measure returns over the following week. While the regression analysis in Section 4.1 is potentially influenced by extreme values of $Z_{t}^{i}$, the returns of sorted portfolios are more robust. The regression analysis imposes a linear relation between $Z_{t}^{i}$ and returns, but the quintiles' average returns are not constrained to be linearly related to the quintiles' average imbalances. The average imbalance is -0.0073 for stocks in the Low- $Z_{t}^{i}$ quintile and +0.0093 for stocks in the High- $Z_{t}^{i}$ quintile.

Table 4, Panel A shows that stocks in the Low- $Z_{t}^{i}$ portfolio have high returns the week after the sorting $\left(r_{t+1}^{i}\right.$ is $+29 \mathrm{bp}$ on average). Stocks in the High- $Z_{t}^{i}$ portfolio have low returns the week after the sorting $\left(r_{t+1}^{i}\right.$ is $-23 \mathrm{bp}$ on average). Similar magnitudes of returns in the extreme quintiles suggest that predictability is not explained by short-selling constraints. A zero-cost portfolio that is long Low- $Z_{t}^{i}$ stocks and short High- $Z_{t}^{i}$ stocks has an average return of $52 \mathrm{bp}$ per week with a $5.36 \mathrm{t}$-statistic. ${ }^{8}$

Table 4, Panel B reports the magnitude of return reversals for different holding periods. We sort stocks by the cumulative trading imbalance over the past one, two, three, and four weeks. The zero-cost portfolio is held for the following one, two, three, and four weeks. The average weekly return of the $\{1,1\}$ portfolio is $52 \mathrm{bp}-$ the same shown in Panel A. Holding the zero-cost portfolio for four weeks raises the return to $92 \mathrm{bp}$. Sorting based on the past four weeks and holding for four weeks is similar to a monthly sort and produces a predictable return of $103 \mathrm{bp}$ with a $3.07 \mathrm{t}$-statistic. When the zero-cost portfolio is held for more than three weeks, returns exceed fixed transaction costs which consist of brokerage fees (as low as $0.0700 \%$ ) and a $0.3000 \%$ tax levied on all stock sales.

Fig. 1 illustrates the contemporaneous price impact associated with the trading imbalances as well as the duration of the subsequent reversal. We plot the price of the zero-cost portfolio (inverted). At time zero, individuals heavily buy (sell) certain stocks and prices increase (decrease) a combined total of 242 bp over the week. Prices then start to revert towards pre-existing levels. Over the first week following portfolio formation, prices fall (rise) $52 \mathrm{bp}$. This $52 \mathrm{bp}$ is the same zero-cost portfolio return shown in Table 4 . The reversion does not end after one week. After four weeks, the reversion is $92 \mathrm{bp}$ in total as shown in the top row of Table 4. When the zero-cost portfolio is held for ten weeks, the total price reversion is $125 \mathrm{bp}$.

Fig. 1 includes results for the subsample of 134 stocks with nonzero margin holdings throughout the entire sample period. As explained in Appendix B, the trading imbalances of some stocks can temporarily have a predictable component due to TSE rules. The 134 stocks in the subsample are not likely to have such a predictable component, and therefore more closely match model assumptions. Fig. 1 shows an initial price

\footnotetext{
${ }^{8}$ Three sets of robustness checks are available upon request: (i) the returns of the zero-cost portfolio cannot be explained by exposure to market returns, nor to HML, SMB, or MOM factors; (ii) the average return of a value-weighted zero-cost portfolio is 58 bp per week with a $4.64 t$-statistic; and (iii) sorting stocks based on daily, rather than weekly, trading imbalances leads to a similar pattern of predictable reversals.
} 
Table 4

Sort results

This table shows the results of a sorting procedure based on trading imbalances. In order to compare imbalances across stocks we use $Z_{t}^{i}$ which is net shares traded for stock $i$ divided by total shares outstanding. Construction of the measure is described in the text. Each week we sort stocks into five quintiles based on $Z_{t}^{i}$. Next week's return is calculated starting with next week's opening price. Panel B sorts stocks into quintiles based on the cumulative past 1, 2, 3, or 4 week's imbalances. We form a portfolio that goes long the bottom quintile and short the top quintile of the sorted stocks. We then hold that portfolio for the next 1, 2, 3, or 4 weeks. The full sample contains 607 firms and is described in the text. The sample period starts 05-Jan-1994 and ends 29-Aug-2002. Data are from the Taiwan Economic Journal. $T$-statistics are based on Newey-West standard errors that are robust to heteroskedasticity and autocorrelation.

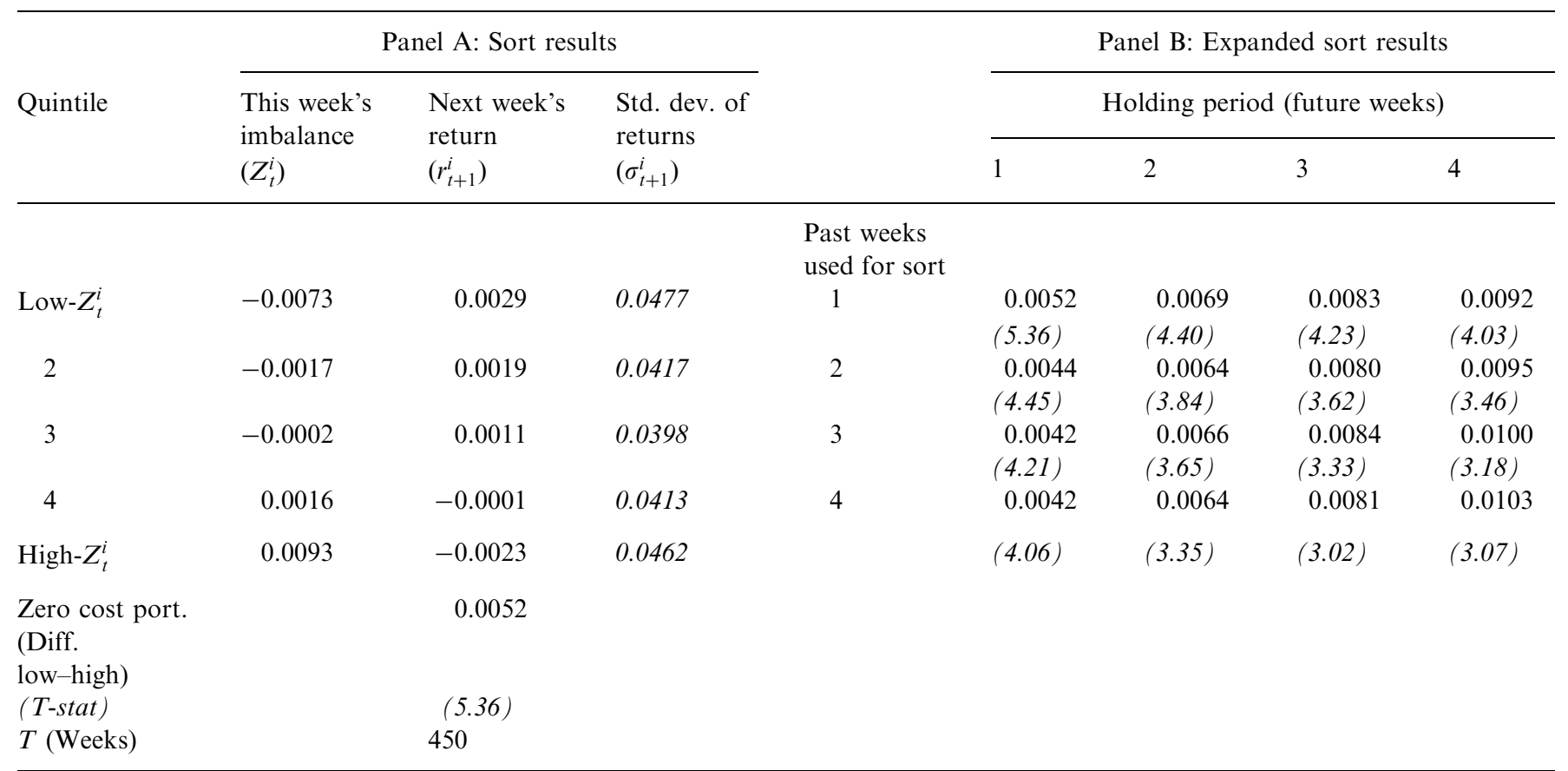

impact of $194 \mathrm{bp}$ for a zero-cost portfolio formed from this subsample of firms. After one week, prices revert $56 \mathrm{bp}$. By the end of ten weeks, prices revert $145 \mathrm{bp}$ in total.

Table 5 reports results of a conditional double-sort procedure which quantifies the economic magnitude of cross-stock price pressure. Each week, we first sort stocks into quintiles based on own-stock trading imbalances $\left(Z_{t}^{i}\right)$. Within each quintile, we subsequently sort stocks into terciles based on the trading imbalances of other stocks in the same industry $\left(Z_{t}^{*}\right)$. Table 5 reports the contemporaneous equal-weighted average return $\left(r_{t}\right)$ for each of the 15 bins. The rows of Table 5 show that, for any level of the own-stock trading imbalance, stock returns are lower when other stocks in the same industry have low trading imbalances $\left(\right.$ Low- $\left.Z_{t}^{*}\right)$. Stock returns are higher when other stocks in the same industry have high trading imbalances $\left(\right.$ High- $Z_{t}^{*}$ ). The return difference between High- $Z_{t}^{*}$ and Low- $Z_{t}^{*}$ stocks (by row) ranges from $111 \mathrm{bp}$ to $189 \mathrm{bp}$. The difference is statistically different from zero at the $1 \%$ level for all $Z_{t}^{i}$ quintiles. Therefore, cross-stock price pressure accounts for a large fraction of the $242 \mathrm{bp}$ price impact at week zero. The total contemporaneous impact based on sorting only by $Z_{t}^{i}$ is 242 bp as shown in Fig. 1 . The 242 bp can be calculated by first taking the average of the bottom and top rows of Table 5 ( $187 \mathrm{bp}$ and $-55 \mathrm{bp}$ ) and then taking the difference of the averages.

\subsection{Additional robustness checks}

We use a conditional double-sort procedure to test whether trading imbalances predict reversals beyond what is predicted using only returns - see Jagadeesh (1990) and Lehmann (1990). Stocks are first sorted into quintiles based on this week's returns $\left(r_{t}^{i}\right)$. Within each quintile, stocks are subsequently sorted into terciles based on trading imbalances $\left(Z_{t}^{i}\right)$. For each return quintile, we calculate the return over the following week of a zero-cost equal-weighted portfolio that is long Low- $Z_{t}^{i}$ stocks and short High- $Z_{t}^{i}$ stocks. The five zero-cost 


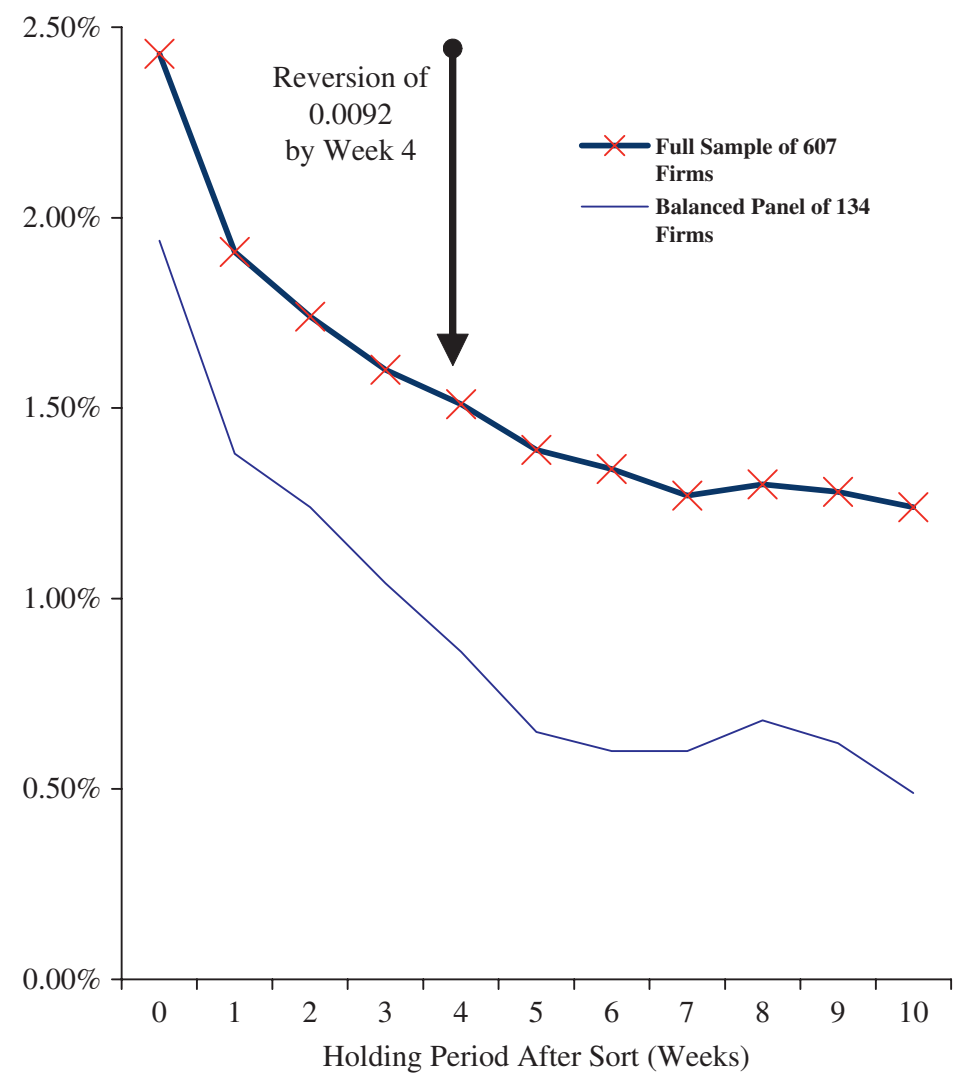

Fig. 1. Price of the zero-cost portfolio (inverted). This figure shows the price of the zero-cost portfolio (inverted) from the time of formation through the following ten-week holding period. $Z_{t}^{i}$ is the measure of trading imbalances over a week. Construction of the measure is described in the text. Shares are sorted at time zero into five quintiles based on $Z_{t}^{i}$. The zero-cost portfolio is long shares in the lowest quintile of $Z_{t}^{i}$ and short shares in the highest quintile. Changes in the inverted portfolio value (Full Sample) represent the same amounts as shown in the first row of Table 4, Panel B. For example, in the first four weeks after the initial sort, the portfolio experiences 0.0092 mean-reversion. Returns are based on weekly open-to-open prices. This figure reports results for the full sample of 607 firms and for the balanced panel of 134 firms. The sample period starts 05-Jan-1994 and ends 29-Aug-2002. Data are from the Taiwan Economic Journal.

portfolios earn $33.6 \mathrm{bp}$ per week on average. The average return is significant at the $1 \%$ level for all but the second-lowest return quintile. Therefore, the trading imbalances predict reversals after controlling for different return levels. In addition, a portfolio that buys $\left\{\right.$ Low- $r_{t}^{i}$, Low- $\left.Z_{t}^{i}\right\}$ stocks and sells $\left\{\right.$ High- $r_{t}^{i}$, High- $\left.Z_{t}^{i}\right\}$ stocks earns 95 bp per week on average. In contrast, a portfolio based on sorting stocks into return quintiles (only) earns $51 \mathrm{bp}$ per week on average.

We use a conditional double-sort procedure to test whether trading imbalances predict reversals beyond what is predicted using only trading volume-see Campbell, Grossman, and Wang (1993). Stocks are first sorted into quintiles based on this week's turnover and are subsequently sorted into terciles based on $Z_{t}^{i}$. The five zero-cost portfolios long Low- $Z_{t}^{i}$ stocks and short High- $Z_{t}^{i}$ stocks earn $34.4 \mathrm{bp}$ per week on average. The average return is significant at the $1 \%$ level in all but the lowest-turnover quintile. Therefore, the trading imbalances predict reversals after controlling for different turnover levels.

\section{Excess volatility}

The model in Section 2 predicts that non-informational trading imbalances lead to excess volatility of stock returns relative to the volatility of discounted future cash flows. From Eq. (2), the variance of stock $i$ 's returns is:

$$
\begin{aligned}
\operatorname{Var}\left(P_{2}^{i}-P_{1}^{i}\right)= & V_{s}+\lambda^{2}\left(V_{\phi}^{2}+V_{s}^{2}\right)\left(V_{z}^{i}+\left(\rho_{\phi}^{*}\right)^{2} V_{z}^{j}+\left(\rho_{\phi}^{* *}\right)^{2} V_{z}^{k}\right. \\
& \left.+2 \rho_{z} \rho_{\phi}^{*}\left(V_{z}^{i}\right)^{\frac{1}{2}}\left(V_{z}^{j}\right)^{\frac{1}{2}}+2 \rho_{z} \rho_{\phi}^{* *}\left(V_{z}^{i}\right)^{\frac{1}{2}}\left(V_{z}^{k}\right)^{\frac{1}{2}}+2 \rho_{z} \rho_{\phi}^{*} \rho_{\phi}^{* *}\left(V_{z}^{j}\right)^{\frac{1}{2}}\left(V_{z}^{k}\right)^{\frac{1}{2}}\right) .
\end{aligned}
$$


Table 5

Conditional double sort and cross-stock price impact

This table shows the results of a conditional double sort procedure based on trading imbalances. In order to compare imbalances across stocks we use $Z_{t}^{i}$ which is net shares traded for stock $i$ divided by total shares outstanding. Construction of the measure is described in the text. Each week we first sort stocks into five quintiles based on $Z_{t}^{i}$. Within each $Z_{t}^{i}$ quintile, we next sort stocks into terciles based on industry imbalance $\left(Z_{t}^{*}\right)$ which excludes the stock's own trading imbalance. Each of the 15 bins shows the contemporaneous week's return. The column "Cross-Stock Price Impact from $Z_{t}^{*}$ " shows the return from the High- $Z_{t}^{*}$ bin minus the return from the Low- $Z_{t}^{*}$ bin for each row. The $T$-statistics of the differences are based on Newey-West standard errors that are robust to heteroskedasticity and autocorrelation. The full sample contains 607 firms and is described in the text. The sample period starts 05-Jan-1994 and ends 29-Aug2002. Data are from the Taiwan Economic Journal.

First sort is by this week's imbalance $\left(Z_{t}^{i}\right)$; second sort is by this week's industry imbalances $\left(Z_{t}^{*}\right)$;

the contemporaneous week's returns $\left(r_{t}^{i}\right)$ shown for each of the 15 bins

\begin{tabular}{|c|c|c|c|c|c|}
\hline & \multirow[b]{2}{*}{ Low $Z_{t}^{*}$} & \multirow[b]{2}{*}{ Med $Z_{t}^{*}$} & \multirow[b]{2}{*}{ High $Z_{t}^{*}$} & \multicolumn{2}{|c|}{$\begin{array}{c}\text { Cross-Stock Price Impact } \\
\text { From } Z_{t}^{*}\end{array}$} \\
\hline & & & & High $Z_{t}^{*}$ Low $Z_{t}^{*}$ & T stat \\
\hline Low $Z_{t}^{i}$ & -0.0131 & -0.0095 & 0.0059 & 0.0189 & $(9.56)$ \\
\hline 2 & -0.0136 & -0.0079 & -0.0007 & 0.0130 & $(10.98)$ \\
\hline 3 & -0.0099 & -0.0043 & 0.0013 & 0.0111 & $(10.35)$ \\
\hline 4 & -0.0036 & 0.0013 & 0.0112 & 0.0149 & $(11.27)$ \\
\hline $\operatorname{High} Z_{t}^{i}$ & 0.0083 & 0.0206 & 0.0271 & 0.0189 & $(8.44)$ \\
\hline
\end{tabular}

Note that the variance of stock returns is equal to the variance of cash flows if $\lambda$ is zero. If the product of any two cash-flow or trading-imbalance correlations $\left(\rho_{\phi}^{*}, \rho_{\phi}^{* *}, \rho_{z}\right)$ is small, the variance of stock $i$ 's returns becomes:

$$
\operatorname{Var}\left(P_{2}^{i}-P_{1}^{i}\right) \approx V_{s}+\lambda^{2}\left(V_{\phi}^{2}+V_{s}^{2}\right) V_{z}^{i}
$$

The equation directly above shows that, after controlling for the variance of cash flows, stocks subject to more volatile trading imbalances have higher return volatilities. Table 6, Panel A shows that the cross-sectional Spearman correlation between the variance of trading imbalances $\left(\sigma_{i, Z}^{2}\right)$ and the variance of stock returns $\left(\sigma_{i, r}^{2}\right)$ is equal to 0.5245 . The correlation is statistically different from zero at the $1 \%$ level.

The high correlation in Panel A could arise spuriously if individuals focus their trading on firms with more volatile cash flows. To address this possibility, we first group stocks by the variance of underlying cash flows. We then compute standardized measures of trading imbalance variance and return variance within each group. To standardize a firm's measure " $x_{i}$ " we calculate

$$
\tilde{x}_{i} \equiv\left(x_{i} \text {-Cross-Sectional Group Average }\right) /(\text { Cross-Sectional Group Standard Deviation })
$$

Finally, we pool data across groups and compute the Spearman correlation of the standardized variances $\left(\tilde{\sigma}_{i, Z}^{2}\right.$ and $\left.\tilde{\sigma}_{i, r}^{2}\right)$.

Table 6, Panel B tests whether stocks with more volatile trading imbalances have more volatile returns after controlling for the volatility of firm cash flows. The table shows results using three alternative grouping methods: (1) sorting firms into quintiles based on the of the variance of gross profits; (2) sorting stocks into quintiles based on the variance of gross profit margin; and (3) sorting stocks into TSE designated industries. When stocks are grouped by the variance of gross profits, the Spearman correlation between $\tilde{\sigma}_{i, r}^{2}$ and $\tilde{\sigma}_{i, Z}^{2}$ is 0.4328 . Correlations are also high when stocks are grouped by the variance of gross-profit margin $(0.4475)$ and by industry (0.3183). All correlations are significant at the $1 \%$ level. Untabulated results show that unstandardized variances $\sigma_{i, z}^{2}$ and $\sigma_{i, r}^{2}$ are significantly correlated within quintiles and within TSE industry groups. Results are similar if stocks are grouped into deciles rather than quintiles. The high correlation coefficients show that stocks with more volatile trading imbalances have more volatile stock returns. 
Table 6

Excess volatility

This table shows the Spearman correlation of the variance of stock $i$ 's weekly trading imbalances $\left(\sigma_{i, Z}^{2}\right)$ and the variance of stock $i$ 's weekly stock returns $\left(\sigma_{i, r}^{2}\right)$. Panel A shows the average correlation across all stocks. Panel B shows the correlation of stock $i$ 's standardized measures of $\tilde{\sigma}_{i, Z}^{2}$ and $\tilde{\sigma}_{i, r}^{2}$. To standardize a variable, we first consider one of three groupings: (1) Quintiles based on stock $i$ 's variance of gross profits; (2) Quintiles based on stock $i$ 's variance of gross profit margin; and (3) TSE industry groups. We then subtract the withingroup average from each variable and divide the result by the within-group standard deviation.

Panel A: Correlation of $\sigma_{i, Z}^{2}$ and $\sigma_{i, r}^{2}$

\begin{tabular}{lcc}
\hline & & All \\
\hline $\begin{array}{c}\text { Spearman Corr. } \\
(p \text {-value })\end{array}$ & $\begin{array}{c}0.5245 \\
(<0.0001)\end{array}$ \\
$\begin{array}{l}\text { Panel B: Correlation of standardized measures of } \tilde{\sigma}_{i, Z}^{2} \text { and } \tilde{\sigma}_{i, r}^{2} \\
\text { quintiles based on the variance } \\
\text { of gross profits }\end{array}$ & $\begin{array}{c}\text { Standardized within } \\
\text { quintiles based on the variance } \\
\text { of gross profit margin }\end{array}$ & $\begin{array}{c}\text { Standardized within } \\
\text { TSE industry groups }\end{array}$ \\
\hline $\begin{array}{c}\text { Spearman Corr. } \\
(p \text {-value })\end{array}$ & $\begin{array}{c}0.4328 \\
(<0.0001)\end{array}$ & 0.4475 \\
\hline
\end{tabular}

\section{Conclusion}

We use trading imbalance data from the Taiwan Stock Exchange to test the implications of a multi-asset equilibrium model in which a finite number of risk-averse liquidity providers accommodate non-informational trading imbalances. The trading imbalance data are derived from the changes in the number of shares held in margin accounts. The data are collected and published by the exchange on a daily basis.

We use regression analysis and a sorting procedure to study the predictable return reversals implied by the model. Sorting stocks into quintiles based on trading imbalances over the week, we show that the difference in contemporaneous returns between stocks in the highest and lowest quintiles is $242 \mathrm{bp}$. A portfolio that sells stocks in the highest quintile and buys stocks in the lowest quintile earns $52 \mathrm{bp}$ per week on average. The portfolio earns $92 \mathrm{bp}$ per week on average if stocks are held four weeks after the initial sort. The two extreme quintiles contain $40 \%$ of listed stocks. Therefore, our results suggest that typical levels of liquidity demand can lead to significant deviations of stock prices from their fundamental values. However, such deviations are temporary. Prices revert towards pre-sort levels over a ten-week period.

Our results also confirm the cross-stock transmission of price pressure predicted by the model. Adding other stocks' trading imbalances to a regression of a stock's weekly returns on its own trading imbalances increases the adjusted $R^{2}$ from $4 \%$ to $21 \%$. Estimated regression coefficients show that cross-stock price pressure is about 2.5 times stronger when the stocks belong to the same industry (and have more correlated fundamentals) than when stocks belong to different industries. Correlations in the model imply two sets of nonlinear restrictions on regression coefficients. We fail to reject the restrictions, which implies that the relative magnitudes of observed cross-stock price pressures are consistent with model predictions. A doublesort procedure indicates that cross-stock price pressure accounts for 111 to 189 of the 242 bp price impact reported in the paragraph above. In total, the results suggest that liquidity is better understood as a marketwide rather than a security-specific attribute, corroborating the results in Chordia, Roll, and Subrahmanyam (2000).

Empirical results support another prediction of the model: stocks with more volatile trading imbalances have more volatile returns. The Spearman correlation between the variance of stock returns $\left(\sigma_{i, r}^{2}\right)$ and the variance of trading imbalances $\left(\sigma_{i, Z}^{2}\right)$ is 0.5245 . Thus, we provide cross-sectional evidence consistent with stock prices being more volatile than discounted future cash flows, which supports results in Shiller (1981). 
A single economic framework relying on a finite number of risk-averse liquidity providers explains several empirical relations between trading imbalances and stock prices. Overall, results suggest that liquidity providers are compensated for absorbing order imbalances. To understand the magnitude of the compensation, one needs to investigate the structure of the market to provide liquidity in Taiwan. Who are the liquidity providers? Do their numbers vary significantly throughout the trading day, week, or year? Do they face capital constraints? Are there implicit and/or explicit barriers to entry? These questions are left for future study.

\section{Appendix A. Model}

Stock $i$ pays a liquidating cash flow at date 3. Therefore, $P_{3}^{i}=\left(S_{1}^{i}+S_{2}^{i}+\Phi_{3}^{i}\right)$. Similar expressions hold for stocks $j$ and $k$. We solve for demands and prices at date 2. Liquidity providers choose their date 2 holdings $\left[\begin{array}{lll}X_{2}^{i} & X_{2}^{j} & X_{2}^{k}\end{array}\right]^{\prime}$ in order to maximize the expected utility of date 3 wealth. The CARA-normal framework implies the following optimal demand at date 2 :

$$
\begin{aligned}
& {\left[\begin{array}{l}
X_{2}^{i} \\
X_{2}^{j} \\
X_{2}^{k}
\end{array}\right]=\frac{1}{\lambda}\left(\operatorname{Var}_{2}\left[\begin{array}{c}
S_{1}^{i}+S_{2}^{i}+\Phi_{3}^{i} \\
S_{1}^{j}+S_{2}^{j}+\Phi_{3}^{j} \\
S_{1}^{k}+S_{2}^{k}+\Phi_{3}^{k}
\end{array}\right]\right)^{-1} E_{2}\left[\begin{array}{c}
S_{1}^{i}+S_{2}^{i}+\Phi_{3}^{i}-P_{2}^{i} \\
S_{1}^{j}+S_{2}^{j}+\Phi_{3}^{j}-P_{2}^{j} \\
S_{1}^{k}+S_{2}^{k}+\Phi_{3}^{k}-P_{2}^{k}
\end{array}\right]} \\
& {\left[\begin{array}{l}
X_{2}^{i} \\
X_{2}^{j} \\
X_{2}^{k}
\end{array}\right]=\frac{1}{\lambda}\left[\begin{array}{ccc}
V_{\phi} & \rho_{\phi}^{*} V_{\phi} & \rho_{\phi}^{* *} V_{\phi} \\
\rho_{\phi}^{*} V_{\phi} & V_{\phi} & \rho_{\phi}^{* *} V_{\phi} \\
\rho_{\phi}^{* *} V_{\phi} & \rho_{\phi}^{* *} V_{\phi} & V_{\phi}
\end{array}\right]\left[\begin{array}{c}
S_{1}^{i}+S_{2}^{i}-P_{2}^{i} \\
S_{1}^{j}+S_{2}^{j}-P_{2}^{j} \\
S_{1}^{k}+S_{2}^{k}-P_{2}^{k}
\end{array}\right]}
\end{aligned}
$$

Market clearing at date 2 implies: $X_{2}^{i}=1-\left(Z_{1}^{i}+Z_{2}^{i}\right)$ along with similar expressions for stocks $j$ and $k$. We substitute the market-clearing conditions into the optimal demand equation and solve for date 2 prices.

At date 1, liquidity providers choose holdings $\left[\begin{array}{lll}X_{1}^{i} & X_{1}^{j} & X_{1}^{k}\end{array}\right]^{\prime}$ in order to maximize the expected utility of date 3 wealth, given their future optimal decisions and their knowledge about future equilibrium prices. Date 3 wealth is

$$
\begin{aligned}
W_{3}= & X_{2}^{i}\left(P_{3}^{i}-P_{2}^{i}\right)+X_{2}^{j}\left(P_{3}^{j}-P_{2}^{j}\right)+X_{2}^{k}\left(P_{3}^{k}-P_{2}^{k}\right)+X_{1}^{i}\left(P_{2}^{i}-P_{1}^{i}\right)+X_{1}^{j}\left(P_{2}^{j}-P_{1}^{j}\right) \\
& +X_{1}^{k}\left(P_{2}^{k}-P_{1}^{k}\right)
\end{aligned}
$$

We substitute the date 2 market-clearing equations for $i, j$, and $k$ and the equilibrium values of $\left\{P_{3}^{i}, P_{3}^{j}, P_{3}^{k}\right\}$ and $\left\{P_{2}^{i}, P_{2}^{j}, P_{2}^{k}\right\}$ into the equation directly above to get date 3 wealth as a function of the vector of date 1 control variables $\left[\begin{array}{lll}X_{1}^{i} & X_{1}^{j} & X_{1}^{k}\end{array}\right]^{\prime}$ :

$$
\begin{aligned}
W_{3}= & X_{1}^{i}\left(S_{1}^{i}+\lambda V_{\phi}\left(Z_{1}^{i}+\rho_{\phi}^{*} Z_{1}^{j}+\rho_{\phi}^{* *} Z_{1}^{k}\right)-\lambda V_{\phi}\left(1+\rho_{\phi}^{*}+\rho_{\phi}^{* *}\right)-P_{1}^{i}\right) \\
& +X_{1}^{j}\left(S_{1}^{j}+\lambda V_{\phi}\left(Z_{1}^{j}+\rho_{\phi}^{*} Z_{1}^{i}+\rho_{\phi}^{* *} Z_{1}^{k}\right)-\lambda V_{\phi}\left(1+\rho_{\phi}^{*}+\rho_{\phi}^{* *}\right)-P_{1}^{j}\right) \\
& +X_{1}^{k}\left(S_{1}^{k}+\lambda V_{\phi}\left(Z_{1}^{k}+\rho_{\phi}^{* *} Z_{1}^{i}+\rho_{\phi}^{* *} Z_{1}^{j}\right)-\lambda V_{\phi}\left(1+\rho_{\phi}^{* *}+\rho_{\phi}^{* *}\right)-P_{1}^{k}\right) \\
& -Z_{1}^{i} \Phi_{3}^{i}+X_{1}^{i} S_{2}^{i}+\lambda V_{\phi} Z_{2}^{i}\left(X_{1}^{i}+2\left(Z_{1}^{i}-1\right)+\rho_{\phi}^{*}\left(X_{1}^{j}+2\left(Z_{1}^{j}-1\right)\right)+\rho_{\phi}^{* *}\left(X_{1}^{k}+2\left(Z_{1}^{k}-1\right)\right)\right) \\
& -Z_{1}^{j} \Phi_{3}^{j}+X_{1}^{j} S_{2}^{j}+\lambda V_{\phi} Z_{2}^{j}\left(X_{1}^{j}+2\left(Z_{1}^{j}-1\right)+\rho_{\phi}^{*}\left(X_{1}^{i}+2\left(Z_{1}^{i}-1\right)\right)+\rho_{\phi}^{* *}\left(X_{1}^{k}+2\left(Z_{1}^{k}-1\right)\right)\right) \\
& -Z_{1}^{k} \Phi_{3}^{k} \\
& +X_{1}^{k} S_{2}^{k}+\lambda V_{\phi} Z_{2}^{k}\left(X_{1}^{k}+2\left(Z_{1}^{k}-1\right)+\rho_{\phi}^{* *}\left(X_{1}^{i}+2\left(Z_{1}^{i}-1\right)\right)+\rho_{\phi}^{* *}\left(X_{1}^{j}+2\left(Z_{1}^{j}-1\right)\right)\right) \\
& -Z_{2}^{i} \Phi_{3}^{i}+\lambda V_{\phi}\left(Z_{2}^{i}\right)^{2}-Z_{2}^{j} \Phi_{3}^{j}+\lambda V_{\phi}\left(Z_{2}^{j}\right)^{2}-Z_{2}^{k} \Phi_{3}^{k}+\lambda V_{\phi}\left(Z_{2}^{k}\right)^{2} \\
& +2 \lambda V_{\phi} \rho_{\phi}^{*} Z_{2}^{i} Z_{2}^{j}+2 \lambda V_{\phi} \rho_{\phi}^{* *} Z_{2}^{i} Z_{2}^{k}+2 \lambda V_{\phi} \rho_{\phi}^{* *} Z_{2}^{j} Z_{2}^{k}
\end{aligned}
$$


Liquidity providers choose $\left[\begin{array}{llll}X_{1}^{i} & X_{1}^{j} & X_{1}^{k}\end{array}\right]^{\prime}$ in order to maximize $E_{1}\left[e^{-\lambda W_{3}}\right]$, given an observed realization of $\left\{S_{1}^{i}, S_{1}^{j}, S_{1}^{k}\right\}$. Date 3 wealth $\left(W_{3}\right)$ is a quadratic function of normal random variables. Therefore, we can apply the following result:

Let $Y \sim \mathrm{N}(\mu, \Sigma)$ and $A$ is symmetric, then:

$$
\begin{aligned}
\mathrm{E}\left[\exp \left(C+B^{\prime} Y-Y^{\prime} A Y\right)\right]= & |\Sigma|^{-\frac{1}{2}}\left|2 A+\Sigma^{-1}\right|^{-\frac{1}{2}} \exp \left(C+B^{\prime} \mu+\mu^{\prime} A \mu\right. \\
& \left.+\frac{1}{2}\left(B^{\prime}-2 \mu^{\prime} A^{\prime}\right)\left(2 A+\Sigma^{-1}\right)^{-1}(B-2 A \mu)\right)
\end{aligned}
$$

where $Y \equiv\left[\begin{array}{lllllllll}\Phi_{3}^{i} & S_{2}^{i} & Z_{2}^{i} & \Phi_{3}^{j} & S_{2}^{j} & Z_{2}^{j} & \Phi_{3}^{k} & S_{2}^{k} & Z_{2}^{k}\end{array}\right]^{\prime}$. The market-clearing condition at date 1 is $X_{1}^{i}=1-Z_{1}^{i}$ with similar expressions for stocks $j$ and $k$. Setting the derivative with respect to $\left[\begin{array}{llll}X_{1}^{i} & X_{1}^{j} & X_{1}^{k}\end{array}\right]^{\prime}$ equal to zero and using the market-clearing conditions at date 1 yields date 1 equilibrium prices.

\section{Appendix B. Subsample selection}

Not all stocks in Taiwan have shares held in margin accounts at all times. In some circumstances, the TSE halts margin trading in a particular stock and requires closure of all margin positions in that stock within a pre-specified time window. These halts are triggered by significant changes in a firm's capital structure or unusually poor operating performance. During the pre-specified time window, the number of that stock's shares held in margin accounts decreases in a predictable fashion (for that stock only). When margin trading in the stock is later resumed, the number of shares held in margin accounts increases in a predictable fashion for some time. In other words, holdings go from zero shares to some steady-state level. Similar predictability occurs after a stock is first listed on the TSE.

Fig. A1 shows the fraction of shares outstanding held in margin accounts for two individual stocks. Shares of ticker 1215 are held in margin accounts throughout the entire sample period. Shares of ticker 2328 experience margin trading halts and associated (temporary) predictable changes in shares held in margin accounts. These temporary periods of predictable changes in the number of shares held in margin accounts

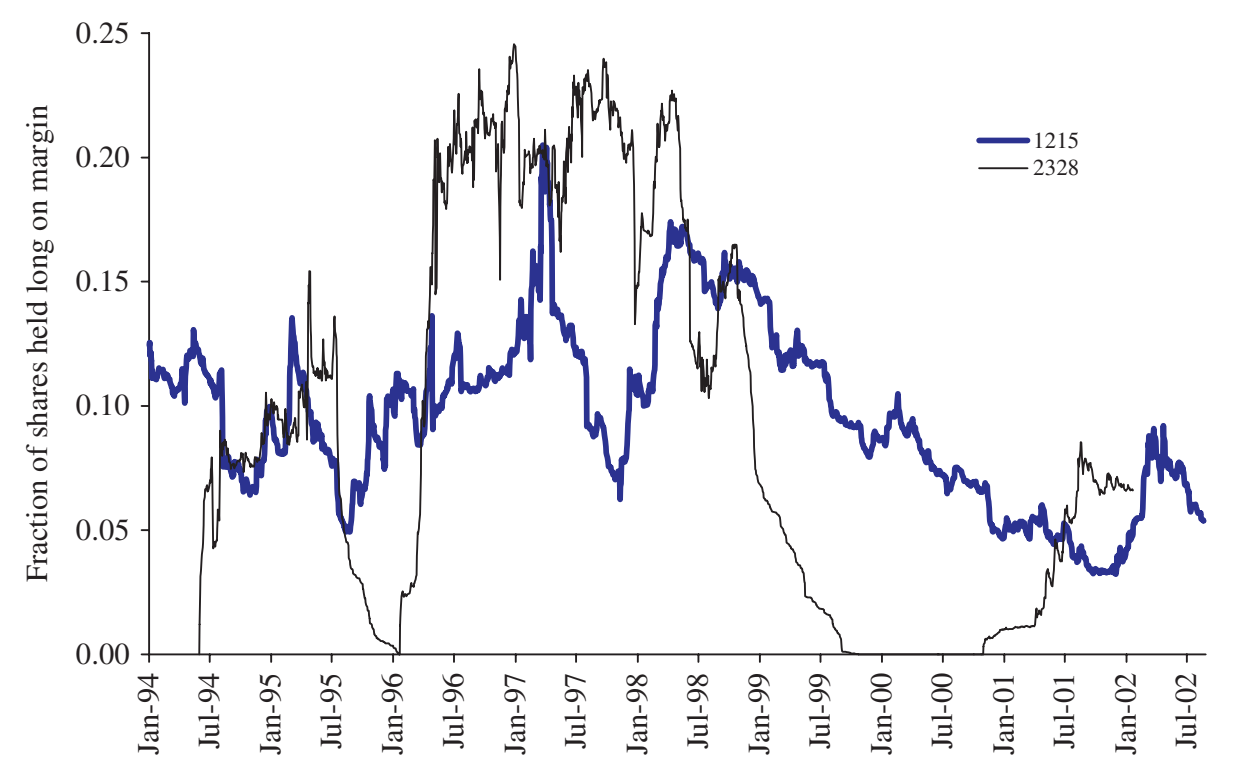

Fig. A1. Holdings for two individual stocks. This figure shows the holdings of two companies' shares from our sample. Holdings data, $H_{t}^{i}$, are available from the Taiwan Stock Exchange and defined as the total number of shares held long in margin accounts divided by total shares outstanding. Construction of this measure is described in the text. The first company (ticker 1215) has positive holdings for the entire time it is listed. The second stock (ticker 2328) has a one-year period where holdings data disappear (i.e., shares of the stock are no longer held in margin accounts). This period is from 1999 to 2000. Thus, ticker 1215 is included in the balanced panel of 134 companies and ticker 2328 is not. The sample period starts 05-Jan-1994 and ends 29-Aug-2002. Data are from the Taiwan Economic Journal. 
violate the assumptions of the model. Therefore, we consider a subsample of 134 companies that have a positive number of shares held in margin accounts during all 451 weeks in our sample period.

\section{References}

Amihud, Y., Mendelson, H., 1980. Dealership markets: marketmaking with inventories. Journal of Financial Economics 8, 31-53.

Avramov, D., Chordia, T., Goyal, A., 2006. Liquidity and autocorrelations in individual stock returns. Journal of Finance 61, 2365-2394.

Barber, B., Lee, Y., Liu, J., Odean, T., 2005. Who loses from trade? Evidence from Taiwan. Unpublished working paper. U.C. Davis.

Barber, B., Odean, T., 2000. Trading is hazardous to your wealth: the common stock investment performance of individual investors. Journal of Finance 55, 773-806.

Barber, B., Odean, T., Zhu, N., 2006. Do noise traders move markets? Unpublished working paper. U.C. Davis.

Barberis, N., Shleifer, A., 2003. Style investing. Journal of Financial Economics 68, 161-199.

Blume, M., Stambaugh, R., 1983. Biases in computed returns: an application to the size effect. Journal of Financial Economics 12, $387-404$.

Campbell, J., Grossman, S., Wang, J., 1993. Trading volume and serial correlation in stock returns. Quarterly Journal of Economics 108, 905-939.

Chordia, T., Roll, R., Subrahmanyam, A., 2000. Commonality in liquidity. Journal of Financial Economics 56, 3-28.

Chordia, T., Roll, R., Subrahmanyam, A., 2002. Order imbalance, liquidity, and market returns. Journal of Financial Economics 65, $111-130$.

Chordia, T., Roll, R., Subrahmanyam, A., 2005. Liquidity and market efficiency. Unpublished working paper. Emory University.

Chordia, T., Subrahmanyam, A., 2004. Order imbalance and individual stock returns: theory and evidence. Journal of Financial Economics 72, 485-518.

DeLong, B., Shleifer, A., Summers, L., Waldman, R., 1990a. Positive feedback investment strategies and destabilizing rational speculation. Journal of Finance 45, 379-395.

DeLong, B., Shleifer, A., Summers, L., Waldman, R., 1990b. Noise trader risk in financial markets. Journal of Political Economy 98 , 703-738.

Denis, D., McConnell, J., Ovtchinnikov, A., Yu, Y., 2003. SP500 index additions and earnings expectations. Journal of Finance 58, $1821-1840$.

Dhillon, U., Johnson, H., 1991. Changes in the standard \& poor's 500 list. Journal of Business 64, 75-85.

Greenwood, R., 2005. Short- and long-term demand curves for stocks: theory and evidence on the dynamics of arbitrage. Journal of Financial Economics 75, 607-649.

Greenwood, R., 2007. Excess comovement of stock returns: evidence from cross-sectional variation in Nikkei 225 weights. Review of Financial Studies, forthcoming.

Grossman, S., Miller, M., 1988. Liquidity and market structure. Journal of Finance 43, 617-637.

Harford, J., Kaul, A., 2005. Correlated order flow: pervasiveness, sources, pricing effects. Journal of Financial and Quantitative Analysis $40,29-55$.

Harris, L., Gurel, E., 1986. Price and volume effects associated with changes in the SP500 list: new evidence for the existence of price pressure. Journal of Finance 41, 815-829.

Hegde, S., McDermott, J., 2003. The liquidity effects of revisions to the SP500 index: an empirical analysis. Journal of Financial Markets 6, 413-459.

Hendershott, T., Seasholes, M., 2007. Market maker inventories and stock prices. American Economic Review, Papers and Proceedings 97, 210-214.

Ho, T., Stoll, H., 1983. The dynamics of dealer markets under competition. Journal of Finance 38, 1053-1074.

Holden, C., Subrahmanyam, A., 2002. News events, information acquisition, serial correlation. Journal of Business 75, 1-32.

Hvidkjaer, S., 2006. Small trades and the cross-section of stock returns. Review of Financial Studies, forthcoming.

Jagadeesh, N., 1990. Evidence of predictable behavior of security returns. Journal of Finance 45, 881-898.

Kaniel, R., Saar, G., Titman, S., 2008. Individual investor trading and stock returns. Journal of Finance, forthcoming.

Lee, Y., Liu, Y., Roll, R., Subrahmanyam, A., 2004. Order imbalances and market efficiency: evidence from the Taiwan stock exchange. Journal of Financial and Quantitative Analysis 39, 327-341.

Lehmann, B., 1990. Fads, martingales, market efficiency. Quarterly Journal of Economics 105, 1-28.

Llorente, G., Michaely, R., Saar, G., Wang, J., 2002. Dynamic volume-return relation of individual stocks. Review of Financial Studies $15,1005-1047$.

Madhavan, A., Smidt, S., 1993. An analysis of changes in specialist inventories and quotations. Journal of Finance 48, $1595-1628$.

O'hara, M., Oldfield, G., 1986. The microeconomics of market making. Journal of Financial and Quantitative Analysis 21, $361-376$.

Petersen, M., 2007. Estimating standard errors in finance panel data sets: comparing approaches. Review of Financial Studies, forthcoming.

Shiller, R., 1981. Do stock prices move too much to be justified by subsequent changes in dividends? American Economic Review 71, 421-436.

Shleifer, A., 1986. Do demand curves for stocks slope down? Journal of Finance 41, 579-590. 
Spiegel, M., Subrahmanyam, A., 1995. On intraday risk premia. Journal of Finance 50, 319-339.

Subrahmanyam, A., 2005a. Distinguishing between rationales for short-horizon predictability of stock returns. The Financial Review 40, $11-35$.

Subrahmanyam, A., 2005b. Lagged order flows and returns: a longer-term perspective. Unpublished working paper, UCLA.

Wurgler, J., Zhuravskaya, E., 2002. Does arbitrage flatten demand curves for stocks? Journal of Business 75, 583-608. 